\title{
Investigations on quality characteristics in gas tungsten arc welding process using artificial neural network integrated with genetic algorithm
}

\author{
Italo do Valle Tomaz ${ }^{1,2}$ (D) $\cdot$ Fernando Henrique Gruber Colaço ${ }^{3,4}$ (D) $\cdot$ Shoaib Sarfraz ${ }^{5}$ (D) $\cdot$ Danil Yu. Pimenov $^{6}$ (D) \\ Munish Kumar Gupta ${ }^{6,7}$ (D) Giuseppe Pintaude ${ }^{4}$ (D)
}

Received: 2 December 2020 / Accepted: 5 February 2021 / Published online: 6 March 2021

(C) The Author(s) 2021

\begin{abstract}
Gas tungsten arc welding (GTAW) technology is widely used in industry and has advantages, including high precision, excellent welding quality, and low equipment cost. However, the inclusion of a large number of process parameters hinders its application on a wider scale. Therefore, there is a need to implement the prediction and optimization models that effectively enhance the process performance of the GTAW process in different applications. In this study, a five-factor five-level central composite design (CCD) matrix was used to conduct GTAW experiments. AISI 1020 steel blank was used as a substrate; UTP AF Ledurit 60 and UTP AF Ledurit 68 were used as the materials of two tubular wires. Further, an artificial neural network (ANN) was used to simulate the GTAW process and then combined with a genetic algorithm (GA) to determine welding parameters that can provide an optimal weld. In welding experiments, five different welding current levels, welding speed, distance to the nozzle, angle of movement, and frequency of the wire feed pulses were used. Using GA, optimal welding parameters were determined: welding current $=222 \mathrm{~A}$, welding speed $=25 \mathrm{~cm} / \mathrm{min}$, nozzle deflection distance $=8 \mathrm{~mm}$, travel angle $=25^{\circ}$, wire feed pulse frequency $=8 \mathrm{~Hz}$. The determination coefficient $\left(\mathrm{R}^{2}\right)$ and RMSE value of all response parameters are satisfactory, and the $R^{2}$ of all the data remained higher than 0.65 .
\end{abstract}

Keywords Artificial neural network · Genetic algorithm · Pulsed GTAW · Multi-objective optimization · Quality characteristics

Shoaib Sarfraz

shoaib.sarfraz@cranfield.ac.uk

Italo do Valle Tomaz

italo.tomaz@iff.edu.br

Fernando Henrique Gruber Colaço

fernandogruber@ifsc.edu.br

Danil Yu. Pimenov

danil_u@rambler.ru

Munish Kumar Gupta

munishguptanit@gmail.com

Giuseppe Pintaude

giuseppepintaude@gmail.com

1 Instituto Federal Fluminense - Laboratório de Ensaios dos Materiais (LEMat), Estrada Cabo Frio - Búzios, s/n - Baía Formosa, Cabo Frio, Rio de Janeiro, Brazil
2 SEAM Research Centre, Department of Engineering Technology, Waterford Institute of Technology, Waterford X91TX03, Ireland

3 Instituto Federal de Santa Catarina, Rua dos Imigrantes, 445 - Rau, Jaraguá do Sul 89254-430, Santa Catarina, Brazil

4 Universidade Tecnológica Federal do Paraná, Câmpus Curitiba - Rua Deputado Heitor Alencar Furtado, 5000, Curitiba, Paraná 81280-340, Brazil

5 Manufacturing Department, School of Aerospace, Transport and Manufacturing, Cranfield University, Cranfield, Bedfordshire MK43 OAL, UK

6 Department of Automated Mechanical Engineering, South Ural State University, Lenin Prosp. 76, 454080 Chelyabinsk, Russia

Key Laboratory of High Efficiency and Clean Mechanical Manufacture, Ministry of Education, School of Mechanical Engineering, Shandong University, Jinan, People's Republic of China 
Table 1 Chemical composition of the AISI 1020 carbon steel and wires

Chemical composition (Weight, \%)

\begin{tabular}{|c|c|c|c|c|c|c|c|c|c|c|c|c|}
\hline & Carbon $\mathrm{C}$ & $\begin{array}{l}\text { Silicon } \\
\mathrm{Si}\end{array}$ & $\begin{array}{l}\text { Manganese } \\
\text { Mn }\end{array}$ & $\begin{array}{l}\text { Chromium } \\
\mathrm{Cr}\end{array}$ & $\begin{array}{l}\text { Molybdenum } \\
\text { Mo }\end{array}$ & $\begin{array}{l}\text { Tungsten } \\
\text { W }\end{array}$ & $\begin{array}{l}\text { Niobium } \\
\mathrm{Nb}\end{array}$ & $\begin{array}{l}\text { Cobalt } \\
\text { Co }\end{array}$ & $\begin{array}{l}\text { Boron } \\
\text { B }\end{array}$ & $\begin{array}{l}\text { Sulfur } \\
\text { S }\end{array}$ & $\begin{array}{l}\text { Impurities } \\
\Pi\end{array}$ & $\begin{array}{l}\text { Iron } \\
\mathrm{Fe}\end{array}$ \\
\hline $\begin{array}{l}\text { AISI } 1020 \\
\text { steel }\end{array}$ & $0.18-0.23$ & - & $0.3-0.6$ & - & - & - & - & - & - & $\begin{array}{l}\operatorname{Max} \\
0.05\end{array}$ & Max 0.04 & Bal. \\
\hline $\begin{array}{l}\text { UTP AF } \\
\text { Ledurit } 60\end{array}$ & 3.34 & 0.82 & 0.314 & 27.00 & 0.026 & 0.007 & - & 0.010 & 0.311 & - & - & Bal. \\
\hline $\begin{array}{l}\text { UTP AF } \\
\text { Ledurit } 68\end{array}$ & 3.41 & 1.05 & 0.228 & 17.88 & - & - & 3.06 & - & & - & - & Bal. \\
\hline
\end{tabular}

\section{Introduction}

Hardfacing is applying filler metal onto a surface, edge, or a point of base-metal of different compositions. As stated by Ramesh et al. [1], in most cases, the deposited metal is harder than the substrate, resulting in the name "hardfacing." As discussed by Chaidemenopoulos et al. [2], weld feed material composition for hardfacing purposes usually contains a high content of carbon and carbide forming elements. According to Bahoosh et al. [3], the concept increases hardness, improves tribological properties, and extends components service life in many engineering applications. Pawar et al. [4] also mentioned that the hardfacing process could improve surface wear resistance or even restore worn-out surfaces. However, as Ahn [5] discussed, hardfacing deposited by the welding process can result in considerable heat-affected zones and susceptibility to crack due to residual stresses imposed by the welding. As presented by [6], low-carbon steels are usually used as a substrate, which reduces the costs and supplies considerable amounts of iron during the welding, which can compromise the desired dilution. Therefore, the two main challenges involved in hardfacing deposition are obtaining crack-free overlay and low dilution.

Many different welding technologies can be implemented in weld surfacing processes. Among these various techniques, D'Oliveira et al. [7] stated that plasma transferred arc welding (PTAW) and gas tungsten arc welding (GTAW) processes are the most widely used in the industry. They provide some advantages, including high accuracy, superior quality weld, and low equipment cost. As observed by [8], another great advantage of these processes is their capability to produce weld beads with low dilution levels, desirable in the hardfacing layer. To get a suitable balance between the designed microstructure and the welded bead's obtained integrity, dilution adjustment is crucial. Zhang et al. [9] deposited hardfacing using a fusion technique obtained by the arc between the tungsten electrode and the additional metal, successfully obtaining a coating with low dilution. Another successful technique for obtaining low dilution was tried by Silwal et al. [10] using hot-wire with resistive arc heat to preheat the wire. Wang et al. [11] presented an innovation in the process of depositing hot-wire GTAW coatings where a
Fig. 1 Experimental setup: a Welding machine; $\mathbf{b}$ welding electrode with other accessories; and $\mathbf{c}$ scheme of the welding torch and wire feeders

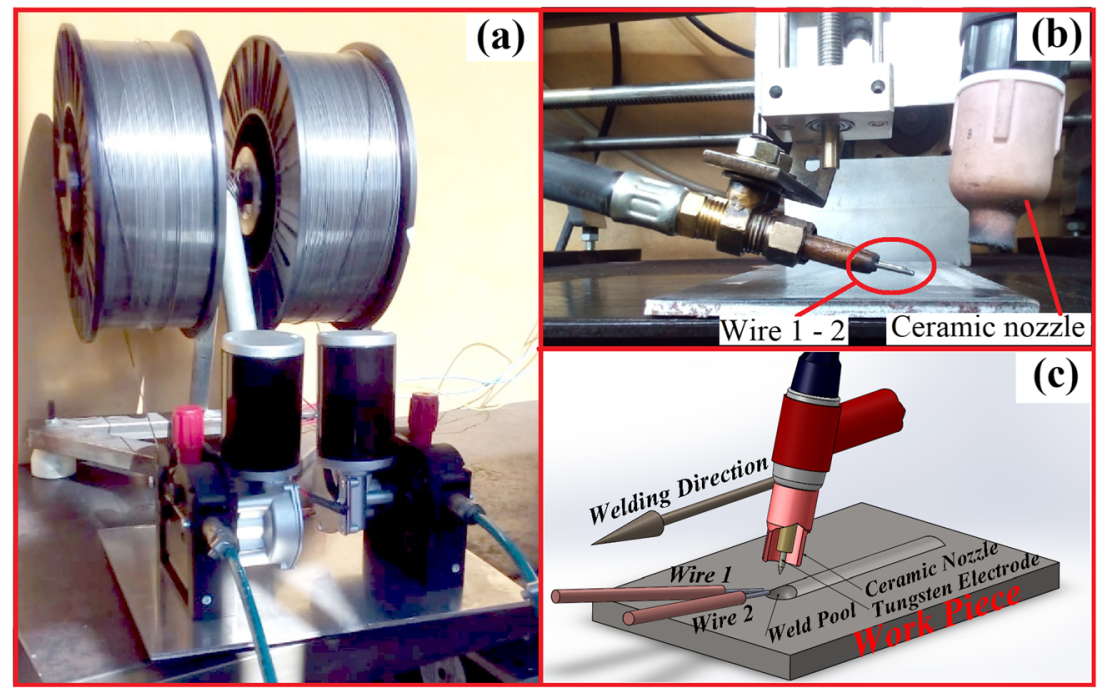


Table 2 GTAW process parameters

\begin{tabular}{ll}
\hline GTAW process parameters & Levels \\
\hline Welding current $(\mathrm{A})$ & $190,210,230,250,270$ \\
Welding speed $(\mathrm{cm} / \mathrm{min})$ & $5,10,15,20,25$ \\
Nozzle standoff distance $(\mathrm{mm})$ & $8,10,12,14,16$ \\
Travel angle $\left(^{\circ}\right)$ & $5,10,15,20,25$ \\
Wire feed pulse frequency $(\mathrm{Hz})$ & $30,45,60,75,90$ \\
\hline
\end{tabular}

secondary bypass arc energy was used to heat the wire. In addition, a promising wire oscillation technique that is being developed by Silva et al. [12] to minimize welding defects can result in significant effects on dilution control. According to Lemke et al. [13], controlling the dilution and composition of the obtained final bead is crucial to ensure desired superficial properties. As observed by Balasubramanian et al. [14], when the GTAW welding process is used in metal deposition, the selection of the proper welding input parameters will define the quality and mechanical, chemical, and also geometric properties of the obtained weld bead. Jahanzaib et al. [15]

Table 3 GTAW parameters with the experimental design and their results

\begin{tabular}{|c|c|c|c|c|c|c|c|c|c|}
\hline \multirow[t]{2}{*}{ Sr. no. } & \multicolumn{5}{|c|}{ GTAW Parameters } & \multicolumn{4}{|l|}{ Responses } \\
\hline & $\begin{array}{l}\text { Welding } \\
\text { current (A) }\end{array}$ & $\begin{array}{l}\text { Welding } \\
\text { speed } \\
(\mathrm{cm} / \mathrm{min})\end{array}$ & $\begin{array}{l}\text { Nozzle } \\
\text { standoff } \\
\text { distance } \\
(\mathrm{mm})\end{array}$ & $\begin{array}{l}\text { Travel } \\
\text { angle }\left(^{\circ}\right)\end{array}$ & $\begin{array}{l}\text { Wire feed } \\
\text { pulse } \\
\text { frequency } \\
(\mathrm{Hz})\end{array}$ & Width (mm) & $\begin{array}{l}\text { Reinforcement } \\
(\mathrm{mm})\end{array}$ & $\begin{array}{l}\text { Penetration } \\
(\mathrm{mm})\end{array}$ & Dilution (\%) \\
\hline 1 & 210 & 10 & 10 & 10 & 75 & $9.65 \pm 1.02$ & $3.62 \pm 0.36$ & $0.60 \pm 0.07$ & $8.80 \pm 1.10$ \\
\hline 2 & 250 & 10 & 10 & 10 & 45 & $14.65 \pm 0.75$ & $2.61 \pm 0.24$ & $1.53 \pm 0.37$ & $26.93 \pm 2.91$ \\
\hline 3 & 210 & 20 & 10 & 10 & 45 & $7.02 \pm 2.45$ & $2.77 \pm 0.52$ & $0.35 \pm 0.22$ & $10.65 \pm 6.86$ \\
\hline 4 & 250 & 20 & 10 & 10 & 75 & $8.88 \pm 0.41$ & $2.31 \pm 0.14$ & $0.80 \pm 0.11$ & $19.74 \pm 3.63$ \\
\hline 5 & 210 & 10 & 14 & 10 & 45 & $12.25 \pm 2.04$ & $3.42 \pm 0.17$ & $0.93 \pm 0.19$ & $15.36 \pm 3.40$ \\
\hline 6 & 250 & 10 & 14 & 10 & 75 & $17.25 \pm 1.12$ & $2.37 \pm 0.25$ & $0.81 \pm 0.23$ & $23.28 \pm 2.35$ \\
\hline 7 & 210 & 20 & 14 & 10 & 75 & $7.69 \pm 2.01$ & $2.57 \pm 1.17$ & $0.19 \pm 0.12$ & $3.51 \pm 2.51$ \\
\hline 8 & 250 & 20 & 14 & 10 & 45 & $9.52 \pm 0.41$ & $2.25 \pm 0.67$ & $0.75 \pm 0.07$ & $16.53 \pm 4.46$ \\
\hline 9 & 210 & 10 & 10 & 20 & 45 & $10.30 \pm 1.39$ & $3.69 \pm 1.30$ & $1.00 \pm 0.12$ & $16.36 \pm 3.73$ \\
\hline 10 & 250 & 10 & 10 & 20 & 75 & $14.46 \pm 0.70$ & $2.56 \pm 0.23$ & $1.10 \pm 0.55$ & $26.17 \pm 5.96$ \\
\hline 11 & 210 & 20 & 10 & 20 & 75 & $7.05 \pm 0.28$ & $2.76 \pm 0.10$ & $0.57 \pm 0.16$ & $12.33 \pm 3.87$ \\
\hline 12 & 250 & 20 & 10 & 20 & 45 & $8.96 \pm 0.52$ & $2.31 \pm 0.28$ & $0.92 \pm 0.19$ & $25.01 \pm 3.98$ \\
\hline 13 & 210 & 10 & 14 & 20 & 75 & $10.29 \pm 1.27$ & $3.70 \pm 0.44$ & $0.54 \pm 0.16$ & $9.35 \pm 2.01$ \\
\hline 14 & 250 & 10 & 14 & 20 & 45 & $16.26 \pm 0.73$ & $2.72 \pm 0.15$ & $1.30 \pm 0.50$ & $23.79 \pm 5.94$ \\
\hline 15 & 210 & 20 & 14 & 20 & 45 & $6.15 \pm 0.61$ & $3.04 \pm 0.27$ & $0.26 \pm 0.07$ & $4.18 \pm 1.40$ \\
\hline 16 & 250 & 20 & 14 & 20 & 75 & $9.34 \pm 0.54$ & $2.24 \pm 0.22$ & $0.56 \pm 0.13$ & $14.90 \pm 2.71$ \\
\hline 17 & 190 & 15 & 12 & 15 & 60 & $5.71 \pm 1.71$ & $3.85 \pm 0.62$ & $0.17 \pm 0.03$ & $3.37 \pm 1.15$ \\
\hline 18 & 270 & 15 & 12 & 15 & 60 & $13.67 \pm 1.72$ & $2.18 \pm 0.17$ & $0.91 \pm 0.19$ & $27.94 \pm 6.78$ \\
\hline 19 & 230 & 5 & 12 & 15 & 60 & $19.20 \pm 3.47$ & $3.19 \pm 0.35$ & $1.53 \pm 0.29$ & $31.90 \pm 6.12$ \\
\hline 20 & 230 & 25 & 12 & 15 & 60 & $7.30 \pm 0.65$ & $2.17 \pm 0.48$ & $0.72 \pm 0.09$ & $8.41 \pm 4.07$ \\
\hline 21 & 230 & 15 & 8 & 15 & 60 & $10.17 \pm 0.92$ & $2.51 \pm 0.49$ & $0.80 \pm 0.12$ & $22.92 \pm 4.72$ \\
\hline 22 & 230 & 15 & 16 & 15 & 60 & $12.48 \pm 1.59$ & $2.48 \pm 0.21$ & $0.49 \pm 0.12$ & $13.13 \pm 2.83$ \\
\hline 23 & 230 & 15 & 12 & 5 & 60 & $8.61 \pm 0.53$ & $2.96 \pm 0.28$ & $0.65 \pm 0.15$ & $15.60 \pm 2.53$ \\
\hline 24 & 230 & 15 & 12 & 25 & 60 & $8.44 \pm 1.13$ & $3.22 \pm 0.26$ & $0.72 \pm 0.12$ & $14.99 \pm 1.40$ \\
\hline 25 & 230 & 15 & 12 & 15 & 30 & $7.92 \pm 0.68$ & $2.73 \pm 0.49$ & $0.84 \pm 0.15$ & $17.34 \pm 2.59$ \\
\hline 26 & 230 & 15 & 12 & 15 & 90 & $9.43 \pm 1.77$ & $2.51 \pm 0.40$ & $0.59 \pm 0.15$ & $16.60 \pm 3.88$ \\
\hline 27 & 230 & 15 & 12 & 15 & 60 & $9.63 \pm 0.50$ & $2.80 \pm 0.15$ & $0.59 \pm 0.12$ & $16.30 \pm 1.64$ \\
\hline 28 & 230 & 15 & 12 & 15 & 60 & $10.39 \pm 0.33$ & $2.71 \pm 0.13$ & $0.59 \pm 0.05$ & $15.06 \pm 3.20$ \\
\hline 29 & 230 & 15 & 12 & 15 & 60 & $10.29 \pm 1.69$ & $2.67 \pm 0.56$ & $0.72 \pm 0.15$ & $18.53 \pm 4.11$ \\
\hline 30 & 230 & 15 & 12 & 15 & 60 & $10.20 \pm 1.96$ & $2.75 \pm 0.57$ & $0.58 \pm 0.10$ & $16.86 \pm 3.97$ \\
\hline 31 & 230 & 15 & 12 & 15 & 60 & $10.11 \pm 1.02$ & $2.77 \pm 0.32$ & $0.78 \pm 0.07$ & $18.84 \pm 3.46$ \\
\hline 32 & 230 & 15 & 12 & 15 & 60 & $10.18 \pm 1.06$ & $2.64 \pm 0.24$ & $0.80 \pm 0.14$ & $18.84 \pm 3.77$ \\
\hline
\end{tabular}


Fig. 2 Deposited weld bead: a Scheme of the geometry and dilution of the bead: W, width; R, reinforcement; $\mathrm{P}$, penetration; $\mathrm{A}$, melted substrate cross-sectional area; B, deposited filler crosssectional area; $\mathbf{b}$ example of an image used to evaluate the dilution

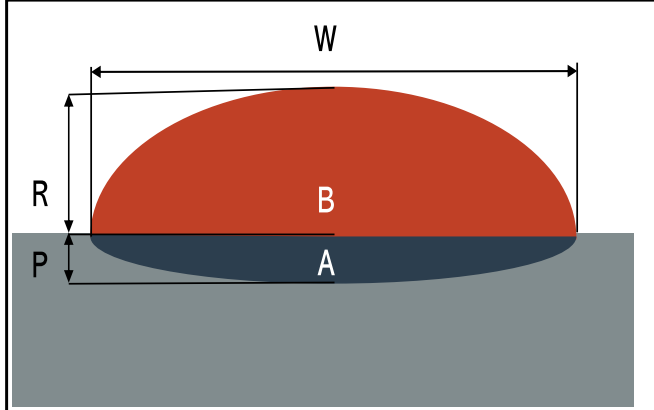

(a)

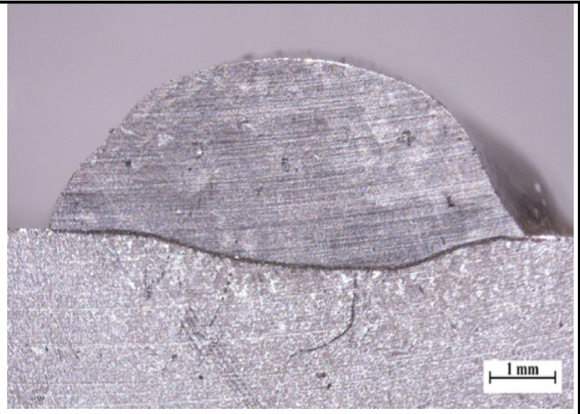

(b) stated that the welding current is an important parameter that most affects the bead geometry responses, and Giridharan and Murugan [16] added that the welding speed is also important, but with an inverse effect on the geometry of the bead. Traditionally, the input parameters of processing are selected based on practical experience and welding engineer experts. Pujari et al. [17] stated that one of the leading welding engineering problems is to use mathematical models that can simulate welding processes and identify the combination of input parameters capable of producing the weld beads with the best possible quality keeping good productivity. Nagesh and Datta [18] used mathematical modeling and design experiments to simulate and predict the welding process results and have proved its efficiency. As discussed by Zheng et al. [19], in industry 4.0, techniques for processing large datasets using artificial intelligence and the integration of artificial intelligence algorithms into automated production are becoming increasingly important. Abubakr et al. [20] also highlighted the importance of artificial intelligence techniques to optimize the manufacturing process, improve components quality, and achieve more sustainable processes.

In this trend, as reported by Fhale et al. [21], many authors have implemented the backpropagation Artificial neural network (ANN) and other artificial intelligence methods to simulate many different manufacturing processes, including welding. Muthu Krishnan et al. [22] used an ANN model to develop regression equations relating to response characteristics and process input parameters for friction stir welding. Vangalapati et al. [23] also simulated friction stir welding using an ANN model. Chang et al. [24] developed a backpropagation ANN model for predicting the penetration morphology of asymmetrical fillet welds and used a mind evolutionary algorithm to optimize the model. Joseph and Muthukumaran [25] used a genetic algorithm and simulated annealing technique to determine the optimal process parameters for activated tungsten inert gas. Sudhakaran and Sakthivel [26] developed neural network models for predicting bead parameters in the GTAW process, such as depth of penetration, bead width, and depth to width ratio. Ghanty et al. [27] also succeeded in using a backpropagation ANN to predict weld bead geometry confirming the method's efficiency. Genetic algorithm (GA) is attracting many researchers' attention to solve optimization problems since traditional optimization methods frequently end up in local minima. GA is beneficial in optimizing multi-objective problems, making it suitable to solve optimization problems related to the manufacturing process that involves many output parameters that must be controlled. Lei et al. [28] applied a GA to
Fig. 3 Artificial neural network architecture

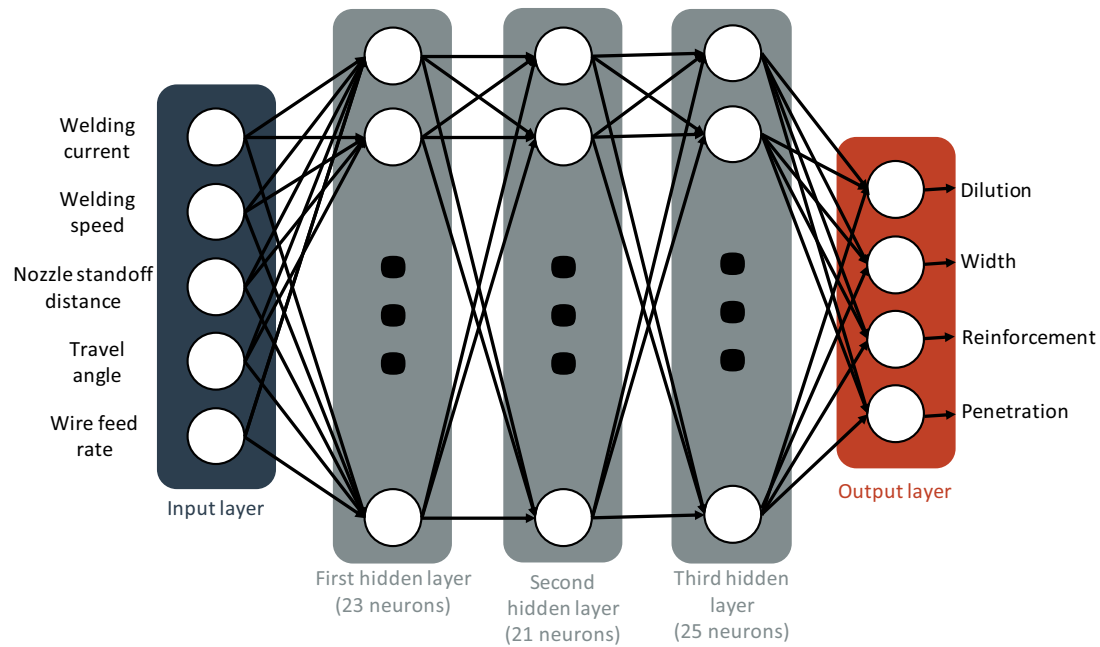




\section{\begin{tabular}{|l|l|l|l|l|l|l|l|l|l|l|l|l|l|l|l|l|l|l|l|l|}
$\mathbf{0}$ & $\mathbf{0}$ & $\mathbf{1}$ & $\mathbf{1}$ & $\mathbf{1}$ & $\mathbf{1}$ & $\mathbf{0}$ & $\mathbf{1}$ & $\mathbf{0}$ & $\mathbf{0}$ & $\mathbf{0}$ & $\mathbf{1}$ & $\mathbf{0}$ & $\mathbf{1}$ & $\mathbf{0}$ & $\mathbf{1}$ & $\mathbf{0}$ & $\mathbf{0}$ & $\mathbf{0}$ & $\mathbf{1}$ \\
\hline
\end{tabular} Welding Welding Nozzle standoff Travel Wire feed}

g. 4 20-digit chromosome used for binary encoding

optimize the ANN used to determine the weld geometry during the thin-plate laser welding of Ti6Al4V. Dey et al. [29] used a GA combined with response surface methodology to minimize weld bead width and height and maximize the weld penetration in electron beam welding, producing a smaller bead without affecting the quality. Multi-objective optimization involves more than one function to be optimized simultaneously. Saha and Mondal [30] investigated the hardfacing process using multi-objective optimization. These authors processed a high volume fraction of metal carbides, metal borides, and boro-carbides finely distributed in a ferritic matrix, designed for wear-resistant components. They found optimum variables for hardfacing layers deposited by manual metal arc welding (MMAW). In the same sense, the multiobjective approach can be found for the GTAW process. For example, Prakash et al. [31] used hybrid optimization algorithms to deposition Inconel 625 alloy onto AISI-304 and 4140 low-alloy steel sheets. Rodriguez et al. [32] investigated the microstructural balance between ferrite and austenite in dissimilar joints of duplex stainless steel through a genetic algorithm. Both cases are aimed at the oil and gas field. Correia et al. [33] reported that GA's capability found optimum welding parameters even when the process's physical model is not available. Although many researchers have been studying the prediction of weld bead geometry and the optimization of GTAW, the literature remains with a lack in the multi-objective optimization of the GTAW hardfacing process. The present investigation used a five-factor, five-level, central composite design (CCD) matrix to run GTAW experiments that were used to train a backpropagation ANN. Five different welding current levels, welding speed, nozzle standoff distance, travel angle, and wire-feed pulse frequency were used in welding experiments. The aim of this work is to use the ANN model coupled to a GA to identify the welding parameters that can produce the optimum weld bead. A final experiment was performed to validate the results of the simulated optimum parameters.

\section{Materials and methods}

\subsection{Welding experiments}

Rectangular samples of AISI 1020 carbon steel with the dimensions of $150 \mathrm{~mm} \times 200 \mathrm{~mm} \times 6 \mathrm{~mm}$ (length $\times$ width $\times$ thickness) were used as substrate. The samples were cleaned and preheated to a temperature of $150^{\circ} \mathrm{C}$ before welding. The chemical composition of AISI 1020 carbon steel is given in Table 1. Weld beads were deposited by the mechanized GTAW process using a Lion 300 welding machine with Argon as shielding gas (at $15 \mathrm{~L} / \mathrm{min}$ ). The nonconsumable tungsten electrode was a $3.2-\mathrm{mm}$ diameter and $1.5 \%$ Lanthanum, installed with direct current in negative polarity. The welding machine was equipped with two wire feeders containing tubular wires with different chemical compositions, as provided in Table 1. Both wires were simultaneously added to the melt pool with a constant wire feed of $2 \mathrm{~m} / \mathrm{min}$ for all experiments. The experimental setup used in the current work, and the welding torch and wire feeders, is shown in Fig. 1.

Fig. $5 \mathrm{ANN}$ and GA procedure

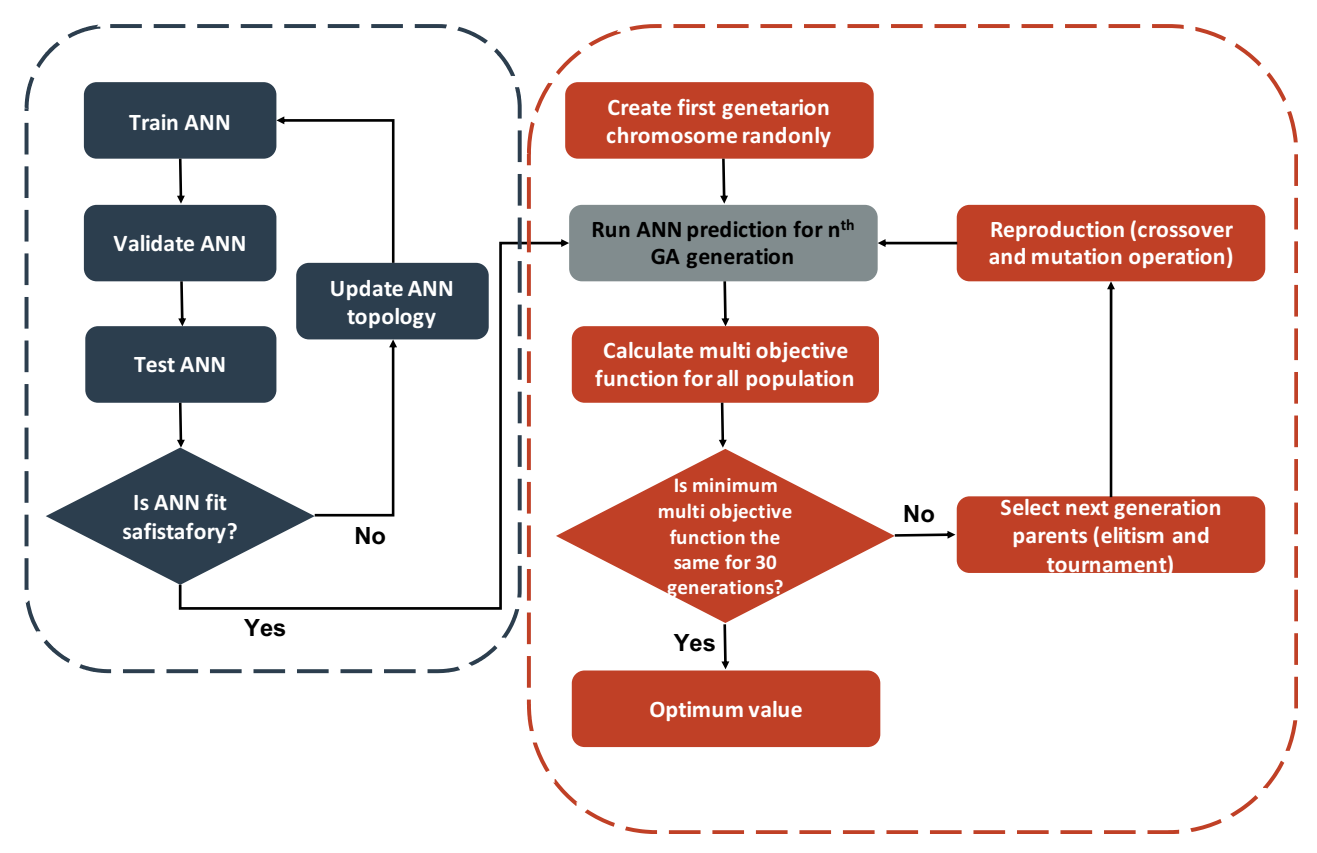




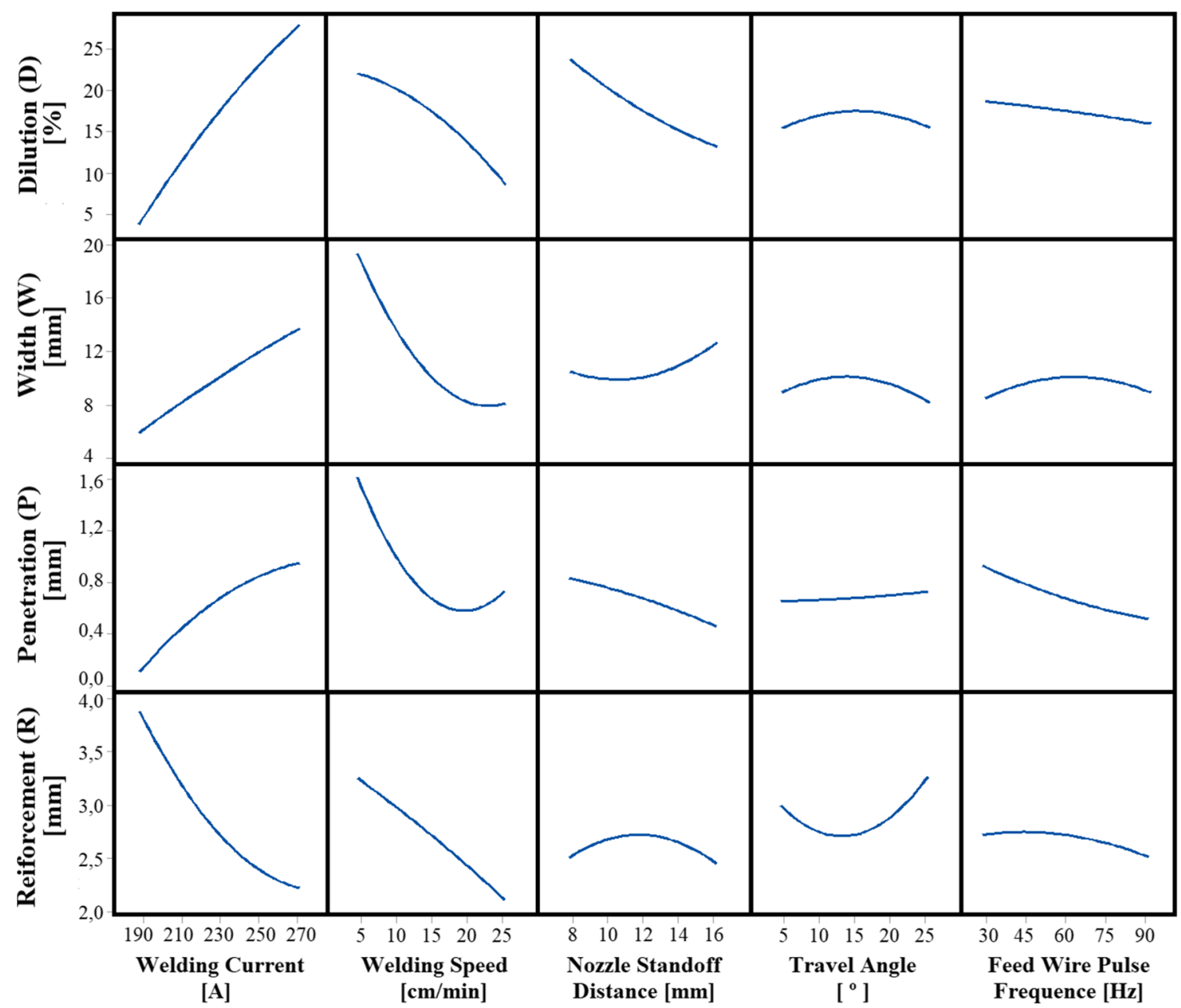

Fig. 6 Main effects plot of GTAW input parameters

The following parameters-welding current, welding speed, nozzle standoff distance, travel angle, and wire feed pulse frequency - were changed as per a five-factor, five-level, central composite design (CCD) matrix. Six replicas were made to each set of parameters. Table 2 exhibits the tested GTAW input parameters and their associated levels.

\subsection{Weld bead quality evaluation}

After the weld bead deposition, samples were cut transversely by electrical discharge machine (EDM) and sanded and polished. Further, images used in the analysis of the width (W), reinforcement $(\mathrm{R})$, penetration $(\mathrm{P})$, and dilution of the bead deposited, which is calculated by the division of penetration crosssectional area (A) by the total cross-sectional area $(\mathrm{A}+\mathrm{B})$, according to Fig. 2a. The images were obtained by the Stemmi-2000 stereoscope and analyzed using the Image-Pro Plus software (Fig. 2b). The experimental data with observed response values and their respective standard deviations are presented in Table 3.

\subsection{Development and modeling of artificial neural network (ANN)}

The ANN model was developed based on experimental data (Table 3). All input data (welding current, welding speed, nozzle standoff distance, travel angle, and wire feed pulse frequency) were normalized to implement $\mathrm{ANN}$, ranging from 0 to 1 as per the following equation (Equation 1):

$X_{i N}=\frac{\left(X_{i}-X_{\min }\right)}{\left(X_{\max }-X_{\min }\right)}$

Where $X_{i N}, X_{i}, X_{\min }$, and $X_{\max }$ are the values of normalized, measured, minimum, and maximum data for each input parameter, respectively. A backpropagation algorithm was used to train the ANN, and a non-linear sigmoid activation function was used. The topology of the used backpropagation neural network consists of five layers: the input layer, three hidden layers, and the output layer. The input layer corresponds to welding parameters having one neuron for each input parameter 
Fig. 7 Comparison of crosssectional areas, illustrating the weld bead of tested conditions 18 , 20 , and 22

Fig. 8 Surface characteristics at different welding parameters

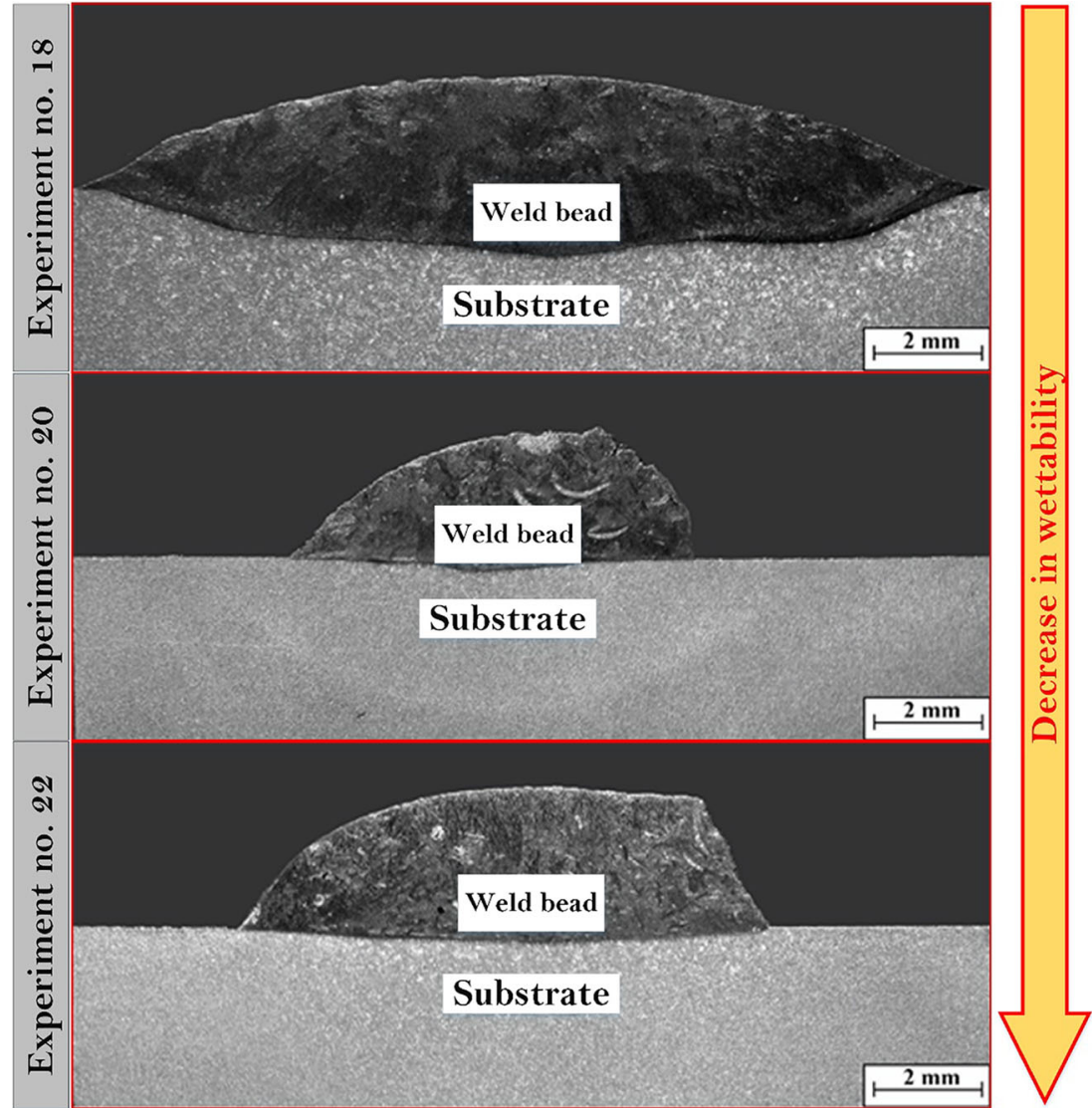

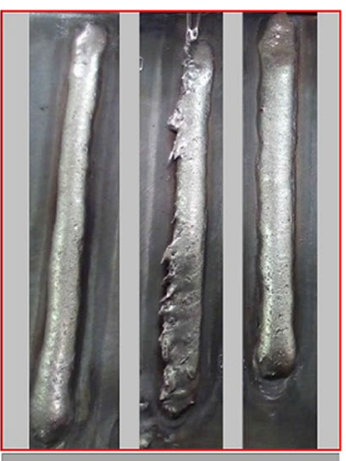

Experiment no. 1

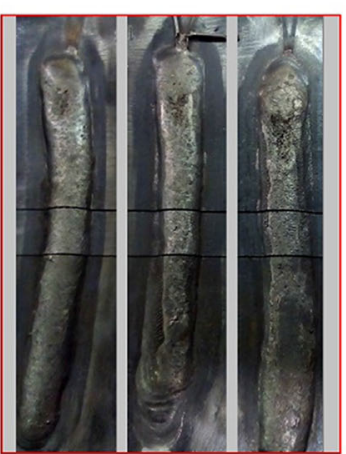

Experiment no. 18

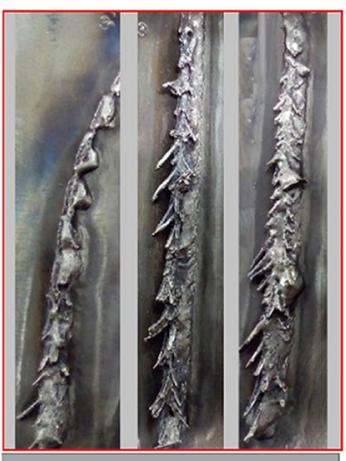

Experiment no. 3

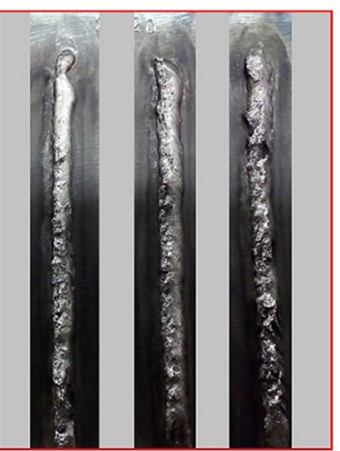

Experiment no. 20

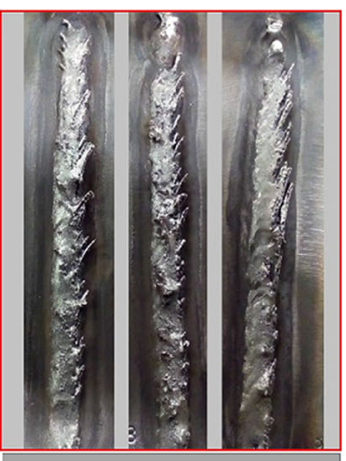

Experiment no. 8

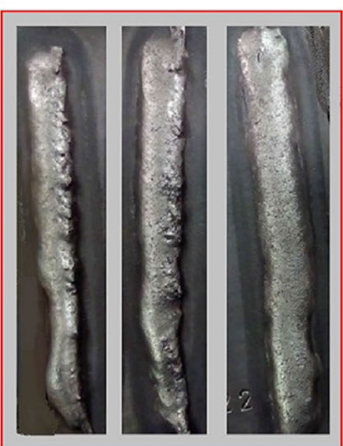

Experiment no. 22 


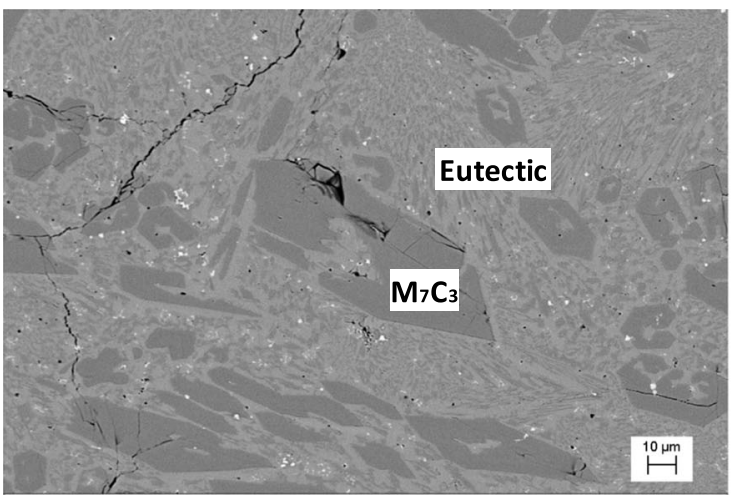

(a)

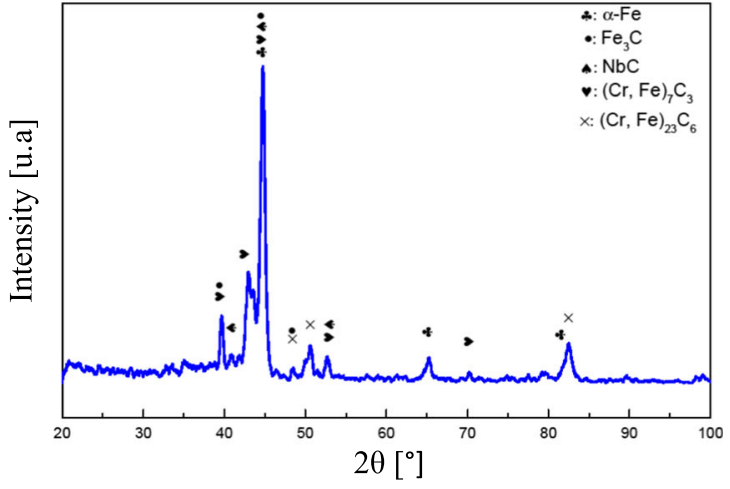

(b)

Fig. 9 SEM image revealing the microstructure of the welded layer of condition 26 (a). Note: microcracks associated with complex carbides. DRX pattern of condition 26 (b)

(welding current, welding speed, nozzle standoff distance, travel angle, and wire feed pulse frequency). The output layer presents four neurons corresponding to output data (width, reinforcement, penetration, dilution). Hidden layer topology was determined by an optimization process, which looked for the topology that provided a higher determination factor value $\left(R^{2}\right)$. This action is considering that the number of hidden layers and neurons plays a vital role in developing an ANN model, and an inadequate architecture can cause overfitting or underfitting of data. Lower root mean square error (RMSE) for all output data when comparing measured and predicted results. The bestidentified topology presents three hidden layers having 23 , 21 , and 25 neurons, respectively. Each neuron of the input layer is connected to each neuron of the first hidden layer. All the following layers followed the same. Figure 3 depicts the topology of ANN according to the studied welding case model. In this study, data set was randomly divided into three sets: training, validation, and testing. The advantage of splitting data into three parts instead of two is to use validation to check when no overfitting in the ANN modeling, avoiding it to produce inferior results when data that were not part of the initial data set is used. The training step used $80 \%$ of the experiment data. After train-

Table 4 Comparison of mean replica experimental uncertainty and ANN relative errors $(\%)$

\begin{tabular}{ccccc}
\hline & Width & Reinforcement & Penetration & Dilution \\
\hline $\begin{array}{c}\text { Experimental } \\
\text { uncertainty }\end{array}$ & 11.84 & 13.31 & 23.89 & 23.63 \\
ANN relative error & 7.96 & 5.13 & 16.79 & 14.58 \\
\hline
\end{tabular}

ing, $10 \%$ of experimental data were used to validate ANN, and the rest $10 \%$ was used to test ANN.

\subsection{Development of genetic algorithm (GA) optimization}

After fitting an appropriate ANN model, a genetic algorithm was adopted to optimize the GTAW process, identifying welding parameters that can improve the deposited weld bead's characteristics, which are represented by an objective function. A binary approach was used for GA implementation; input data were coded in a 20-digit binary code chromosome, as illustrated in Fig. 4.

The adopted procedure in which an artificial neural network was coupled with a GA is shown in Fig. 5. The gray color can identify the coupling step. For each GA generation, the ANN was used to simulate the welding output data. The necessary steps shown in Fig. 5 are as follows:

Step 1 Create a first-generation chromosome randomly: First-generation chromosomes are randomly created. Twenty individuals are created as the first parents.

Step 2 Run ANN prediction for $n^{\text {th }}$ GA generation: In this step, the binary number of each input parameter is converted to a decimal number ( 0 to 15 for all input parameters) and then normalized, ranging from 0 to 1 and used as ANN inputs.

Step 3 Calculate multi-objective function for all populations: After running the ANN, the simulated responses are used to calculate an objective function. This objective function is determined by Equation 2 in which all output parameters were normalized, ranging from 0 to 1 : 
Fig. 10 ANN regression plot for width a training, $\mathbf{b}$ validating, $\mathbf{c}$ test, and $\mathbf{d}$ overall

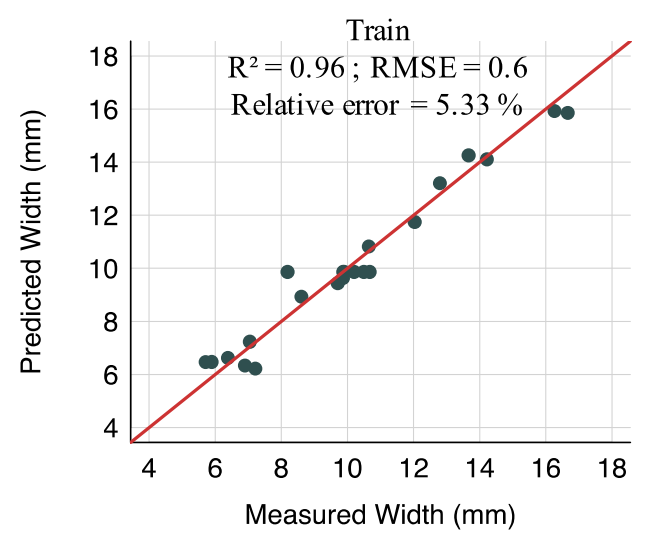

(a)

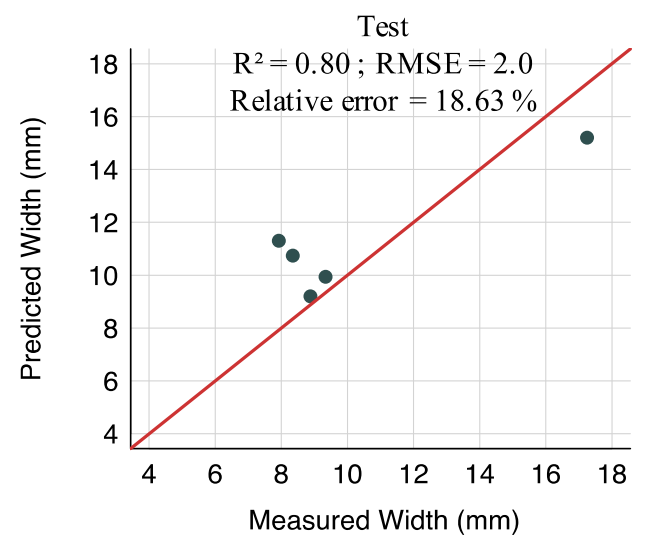

(c)

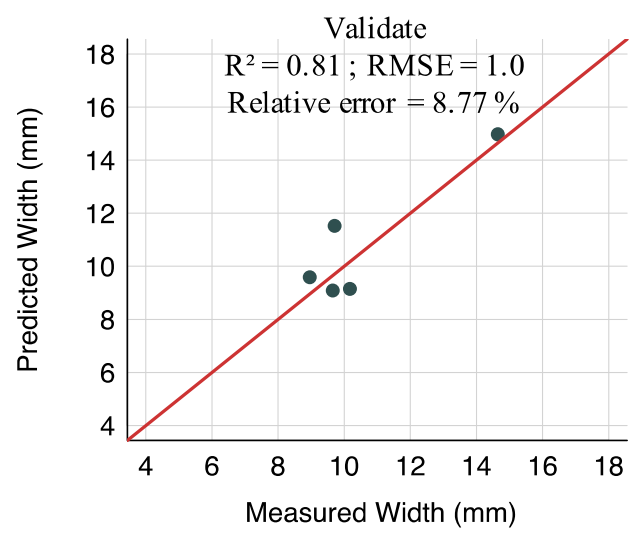

(b)

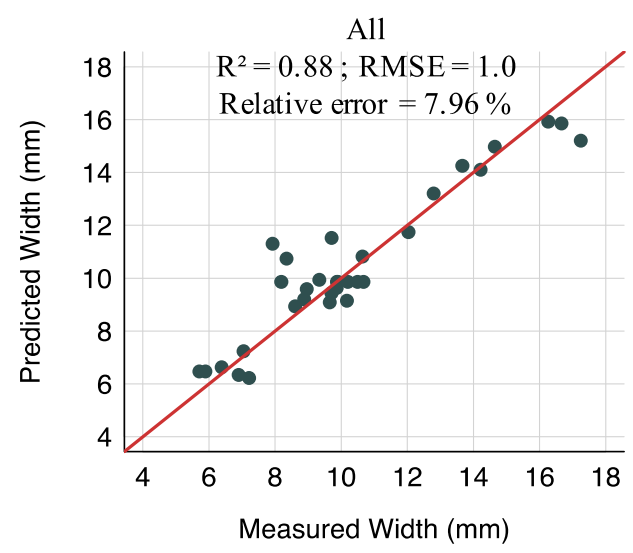

(d)

$$
\begin{gathered}
O F=\frac{W-W_{\min }}{W_{\max }-W_{\min }}+\frac{R-R_{\min }}{R_{\max }-R_{\min }}-\frac{P-P_{\min }}{P_{\max }-P_{\min }}-\frac{D i-D i_{\min }}{D i_{\max }-D i_{\min }} \\
+\left(\frac{\frac{W-W_{\min }}{\frac{W_{\max }-W_{\min }}{R-R_{\min }}}}{R_{\max }-R_{\min }}\right)
\end{gathered}
$$

where $O F$ is the objective function and $W, R, P$, and $D i$ correspond to width, reinforcement, penetration, and dilution, respectively. The min and max index referred to the minimum and maximum values for each output and were used for normalization purposes. The objective function is the mathematical representation of the desired geometry of the weld bead, minimizing width, reinforcement, and their quotient at the same time that penetration and dilution are maximized. It is important to highlight that it consists in a multiobjective optimization and result will present a geometry that will combine and balance all these requirements. At the end of this step, the objective function value is compared with the previous generation value, and if it remains the same for 30 generations, the GA is stopped. The calculated value is determined as the optimum value. This procedure aims to ensure that the whole search space was examined and the global optimum was identified. On the other hand, if the objective function values decrease, the GA move to step 4.

Step 4 Select next-generation parents (elitism and tournament): In the selection step, 20 individuals are selected to be the next generation's parents. In the first generation, all the 20 individuals are randomly created and parents, but 20 individuals are selected from the 40 available (previous and new generation) in the following generations. Elitism is responsible for the selection of $10 \%$ of next-generation parents. In this procedure, all individuals are ranked by the objective function (low to high). The twenty (10\% of the total of 20 parents of next generation) individuals with the lowest objective function value are selected. The other 18 (90\% of the total of 20 parents of nextgeneration) parents are selected using tournament selection described by [34]. The tournament selection consists of selecting randomly 5 individuals and choose the best (lower objective function 
value) to be a parent of the next generation. Bhunia and Samanta [35] stated that tournament selection is the most effective selection method for minimization problems, and it is essential to find the global solution, avoiding local minimums as mentioned by Kılıç and Yüzgeç [36].

Step 5 Reproduction (crossover and mutation): The crossover was used as the main reproduction procedure. In the crossover, two parents are randomly selected, and their chromosomes are split at a random point and then combined to produce two new individuals. This step is repeated ten times using twenty parents. After finishing the crossover, $20 \%$ of the generated individuals are submitted to mutation, which consists of changing the value of one digit of their chromosomes. Finally, the new individuals are submitted to step 2, and the GA continues until the stop criterion is reached. After identifying the optimum welding parameters, a new set of experiments was conducted to validate the optimized welding condition's predicted outputs.

\section{Results and discussion}

\subsection{Influence of GTAW parameters on the quality of weld bead}

Figure 6 presents the effects of GTAW input parameters (welding current, welding speed, nozzle standoff distance, travel angle, and wire feed pulse frequency) on the deposited weld bead geometry (width, reinforcement, penetration, dilution). The graphs were constructed in Minitab17 $®$ and consist in the experimental data plotting joined by an interpolation function intending to evaluate the effects of GTAW variables on the measured values.

Higher welding currents increase heat input and the welding pool and substrate temperature, resulting in more deposited material fluidity. It is possible to note that increments in welding current increased width, penetration, and dilution. The reinforcement, however, decreased when higher welding currents were used. These characteristics can be observed in Fig. 7, which shows the cross-section of a sample welded in condition 18 of Table 3. Condition 18 used the higher tested welding current $(270 \mathrm{~A})$, resulting in a low-quality weld bead
Fig. 11 ANN regression plot for reinforcement (a) training, (b) validating, (c) test, and (d) overall

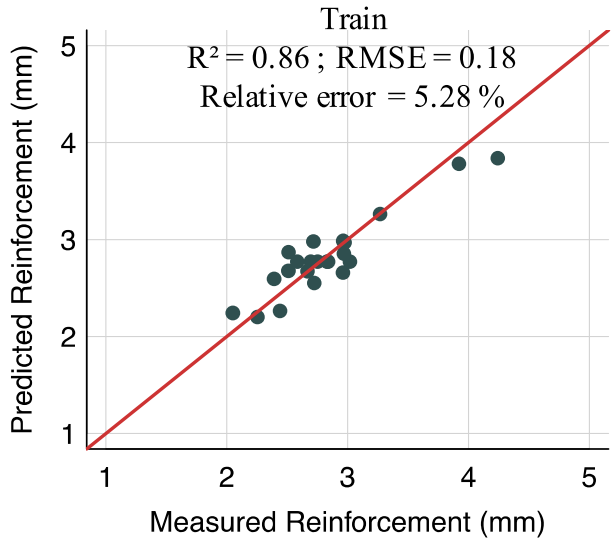

(a)

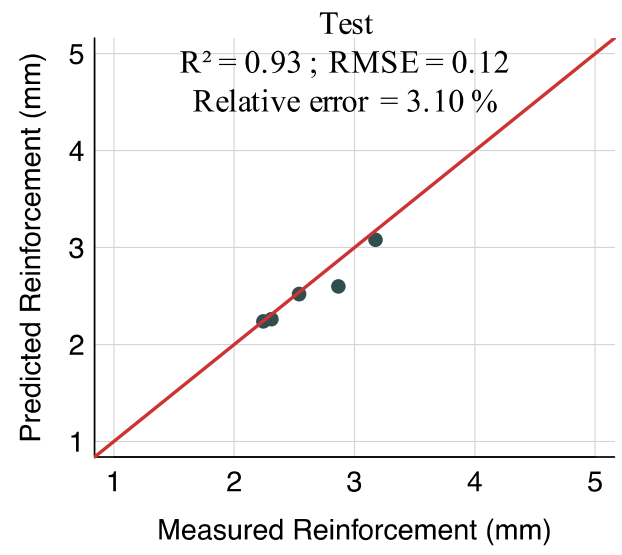

(c)

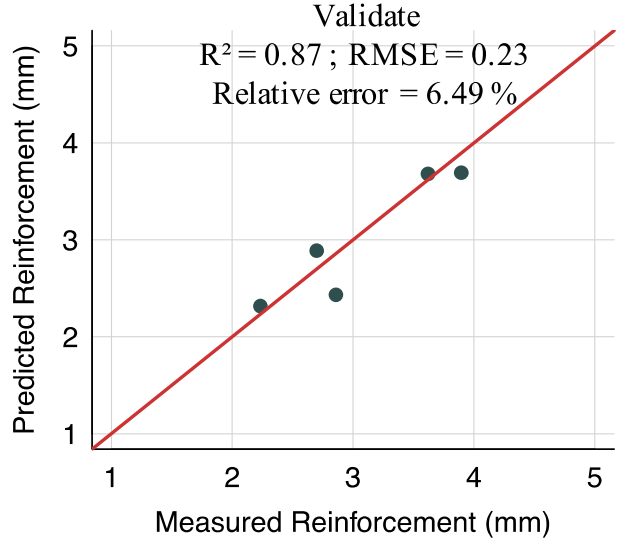

(b)

All

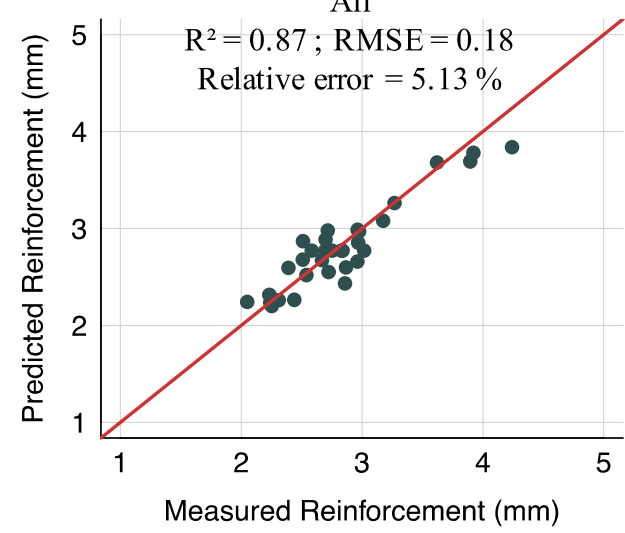

(d) 
Fig. 12 ANN regression plot for penetration (a) training, (b) validating, (c) test, and (d) overall

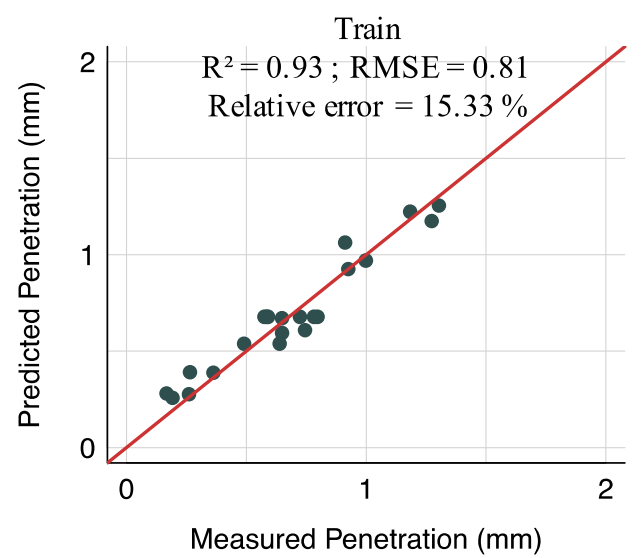

(a)

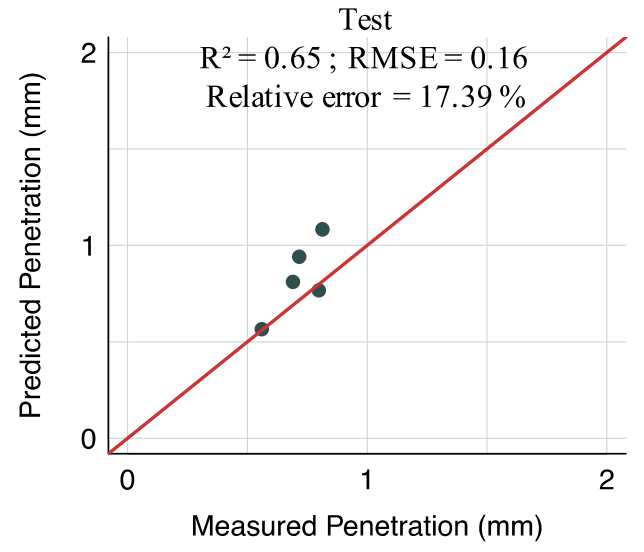

(c)

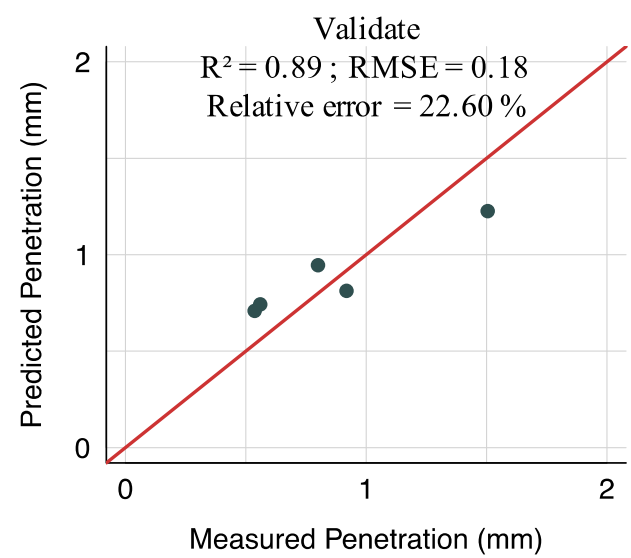

(b)

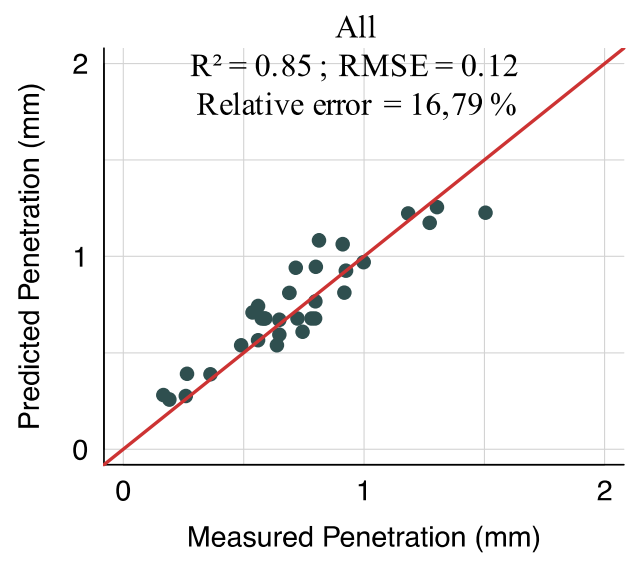

(d) with high dilution. Shanmugam and Murugan [37] reported similar results.

On the other hand, as Balasubramanian et al. [14] reported, welding speed increments reduce heat input generating the opposite effects. Tarng and Yang [38] observed that higher welding speed values resulted in lower response values for all outputs. Figure 7 illustrates the cross-section of a sample welded in condition 20 of Table 3 in which the higher welding speed was used. In these conditions, the obtained dilution is too low, leading to decreased ductility of the overlay near the fusion line resulting from the increasing carbide content [39]. The lowest heat input was not enough to melt all the feed wire, promoting regions rich in iron from the wire structure. The lack of melting can also result in voids formation [40], which can promote cracks when the overlayer is subject to the wear process. Modifications in nozzle standoff distance did not significantly impact reinforcement and penetration but changed width and dilution considerably. Higher values of nozzle standoff resulted in higher width and lower dilution. Figure 7 shows the cross-section of a sample welded in condition 22 of Table 3 . This condition used the higher tested welding speed $(25 \mathrm{~cm} / \mathrm{min})$ combined with the other input parameters generated a desired weld bead geometry. On the contrary, the lower tested welding speed ( $5 \mathrm{~cm} / \mathrm{min}$, condition 19, Table 3 ) produced a weld bead with dilution higher than $30 \%$, which compromises its microstructure and integrity. Travel angle and wire feed pulse frequency did not influence the outputs as the other input parameters. For all the tested interval, they just caused small variations on the response values. A global comparison among Fig. 7 allows concluding that the wettability decreased from condition 18 to condition 22 , being condition 20, an intermediate situation. It is possible to notice that the wettability was influenced by a combination effect of welding current and speed. Moreover, Fig. 8 presents the surface quality characteristics of different combinations of welding parameters. The results are in good agreement with Fig. 7. However, experiment no. 3 shows the poor quality characteristics as compared with all other conditions such as lack of fusion of the wire. In the experiments carried out by Han et al. [41], they also noticed the lack of fusion of the wire and its appearance on the surface of the bead. The authors tested the maximum deposition rate with a double electrode in the GTAW process. These defects were observed at high wire feed speeds 
Fig. 13 ANN regression plot for dilution (a) training, (b) validating, (c) test, and (d) overall

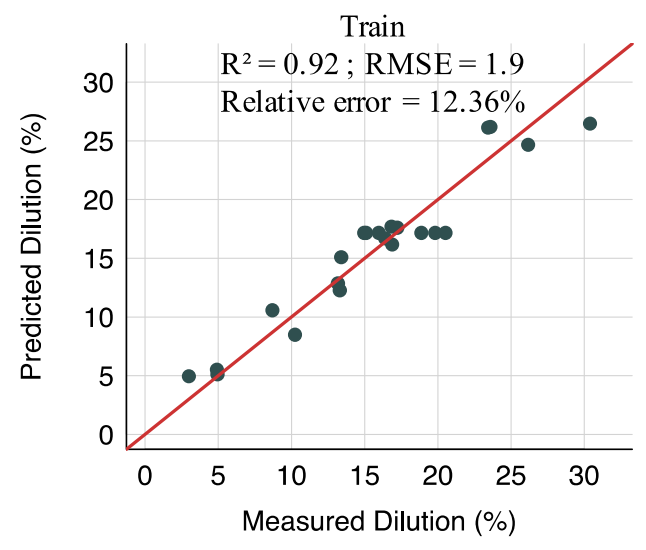

(a)

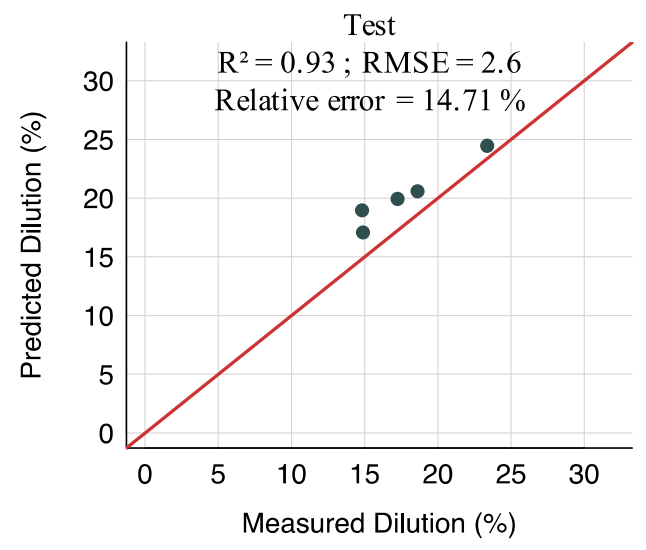

(c)

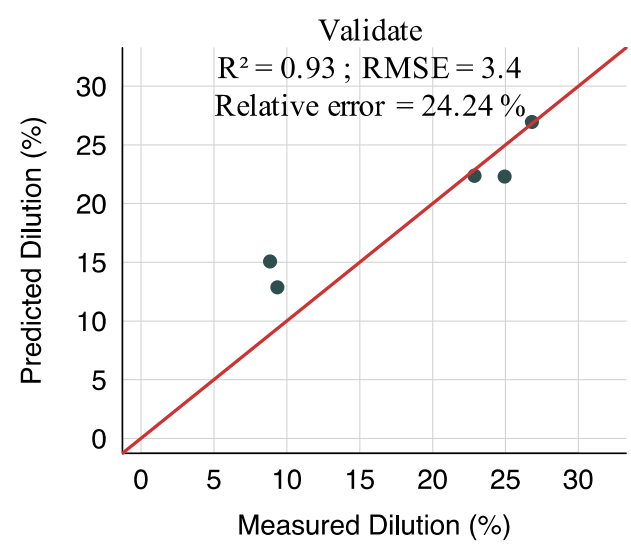

(b)

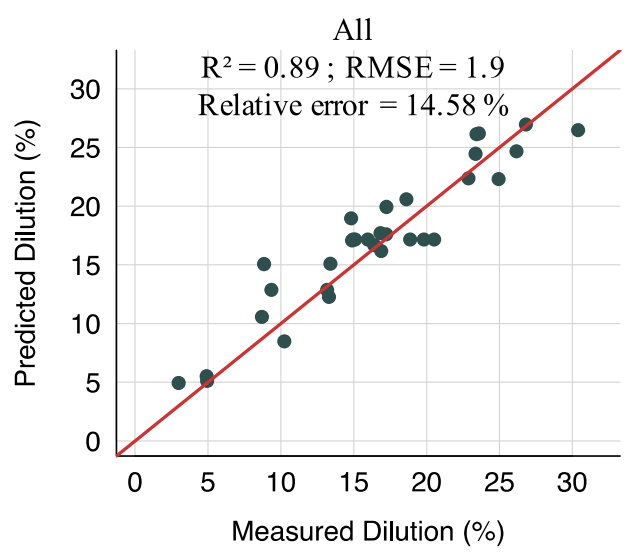

(d) where it was limited by the heat of the arc being insufficient to melt the wire, this causes the wire to hit the bottom of the fusion pool and be directed to the surface of the bead, as was also observed in Fig. 8. This analysis is currently made on single beads. However, during the processing of a hardfacing, multiple layers are interposed on top of each other. A consequence of low wettability is the possible creation of voids, giving rise to a poor adhesion among layers. Also, the resulting microstructure is less and less dependent on the dilution level because further interaction will occur among layers. Besides the bead quality, defined in the previous examples by the geometry and dilution, the resulting microstructures are crucial for abrasive wear situations where the studied hardfacing can be applied.

Lack of fusion of the wire structure and microcracks can weaken the formed microstructure and impair the abrasion resistance. The resulting microstructure of condition 26 is presented in Fig. 9. The wire composition suggests a hypereutectic microstructure. It is composed of primary M7C3 carbides with a eutectic matrix (austenite plus M7C3 carbides). The SEM image and XRD diffractogram confirm this expectation. A local chemical composition performed through the energy-dispersive X-ray spectroscopy on the largest carbide showed the presence of chromium (37.8\% wt.) and iron ( $48.2 \%$ wt.), meaning that it is a complex carbide, probably of $(\mathrm{Fe}, \mathrm{Cr})_{7} \mathrm{C}_{3}$ stoichiometry. Microcracks are observed along with the microstructure of Fig. 9. Some of them are bifurcated, but many of them are restricted to carbide areas. The nucleation of microcracks associated with the carbides, also described by Bahoosh et al. [42], is a combination of the residual stresses level imposed by the welding process and the low fracture
Table 5 Optimum GTAW welding parameters

\begin{tabular}{lllll}
\hline $\begin{array}{l}\text { Welding } \\
\text { current }(\mathrm{A})\end{array}$ & $\begin{array}{l}\text { Welding speed } \\
(\mathrm{cm} / \mathrm{min})\end{array}$ & $\begin{array}{l}\text { Nozzle standoff } \\
\text { distance }(\mathrm{mm})\end{array}$ & $\begin{array}{l}\text { Travel angle } \\
\left({ }^{\circ}\right)\end{array}$ & $\begin{array}{l}\text { Wire feed pulse } \\
\text { frequency }(\mathrm{Hz})\end{array}$ \\
\hline 222 & 25 & 8 & 25 & 30 \\
\hline
\end{tabular}




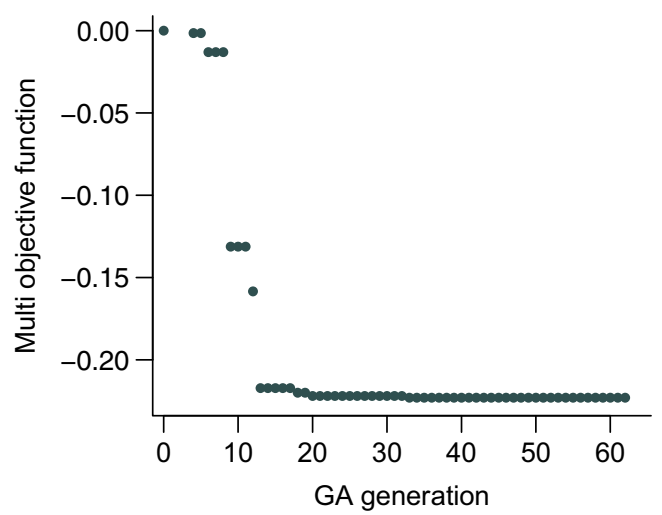

Fig. 14 Objective function value convergence

toughness carbides [43], which is not supported by the metallic matrix.

\subsection{ANN validation}

ANN model performance is shown in Figs. 10, 11, 12, and 13. It is possible to compare predicted and measured data for dilution, width, reinforcement, penetration, respectively. The determination coefficient $\left(\mathrm{R}^{2}\right)$ and RMSE value of all response parameters are satisfactory, and the $\mathrm{R}^{2}$ of all the data remained higher than 0.65 . Table 4 presents the comparison of replica experimental uncertainty and the relative errors between measured and predicted responses. It is possible to see that to all output parameters, and the ANN relative error is smaller than the experimental uncertainty, which means that the neural network model has a robust predictive performance.

\subsection{GA implementation and optimum parameters validation}

After training and verification, the ANN was coupled with the GA to identify the optimum welding parameters. The procedure illustrated in Fig. 14 shows the objective function value over all the sixty-three generations. It is possible to see that it

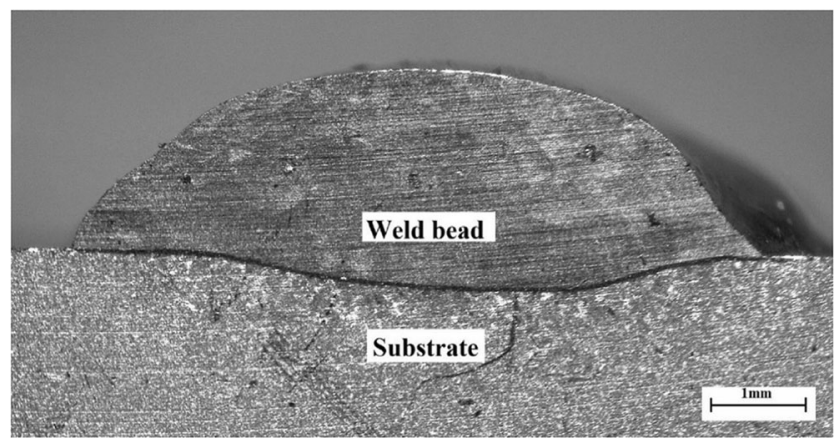

Fig. 15 Cross-section of a bead deposited with an optimized condition reached its minimum after 33 generations and kept the same value for the following thirty generations, reaching the established stop criteria. The optimum welding parameters obtained after a complete evaluation of GA and their corresponding outputs are presented in Table 5. However, the optimized condition presented in Table 5 was used to obtain beads and verify the simulation's reliability. Figure 15 shows the cross-section of a deposited bead with an optimized condition. It is possible to notice that the cord geometry was uniform with width, penetration, and adequate reinforcement, contributing to a bead with low dilution.

Table 6 exhibits a comparison between the predicted and measured outputs for the optimum welding condition. The results presented for the measured results correspond to the mean value of the 35 measures used to verify the predicted outputs. It is possible to see that the relative error is smaller than the observed experimental uncertainty for width, penetration, and dilution of the predicted results. Only the predicted results for reinforcement was beyond the expected error. However, the most relevant remark is that the observed error is similar to the experimental reinforcement standard deviations.

\section{Conclusions}

In this paper, the effect of pulsed GTAW welding parameters in weld bead quality was investigated and a multi-objective optimization was used to identify the best input parameter combination. Based on experiments performed with two tubular wires with different chemical compositions deposited on an AISI 1020 steel substrate, the following conclusions can be put forward:

- The experimental results allowed the comprehension of the influence of each input parameter in the quality of weld beads. Decreasing the welding speed and/or increasing the welding current leads to an increase in the dilution percentage compromising weld bead quality.

- The welding current and speed are the processing parameters that most affect heat input and melting. Therefore, they were the most critical process parameters to determine the geometry and dilution of the weld beads deposited with two tubular wires by the GTAW process.

- An artificial neural network (ANN) was used to simulate the GTAW process and then combined with a genetic algorithm (GA) to determine welding parameters that can provide an optimal weld, which can be integrated into automated production.

- Using GA, optimal welding parameters were determined: welding current $=222 \mathrm{~A}$, welding speed $=25 \mathrm{~cm} / \mathrm{min}$, nozzle stand-off distance $=8 \mathrm{~mm}$, travel angle $=25^{\circ}$, wire feed pulse frequency $=30 \mathrm{~Hz}$. 
Table 6 Predicted and measured outputs for the optimum welding condition

\begin{tabular}{lllll}
\hline & Width $(\mathrm{mm})$ & Reinforcement $(\mathrm{mm})$ & Penetration $(\mathrm{mm})$ & Dilution $(\mathrm{mm})$ \\
\hline Measured & 7.27 & 1.99 & 0.52 & 14.91 \\
Predicted & 6.51 & 2.62 & 0.64 & 15.61 \\
Relative error & $10.45 \%$ & $31.66 \%$ & $23.08 \%$ & $4.69 \%$ \\
\hline
\end{tabular}

- The determination coefficient $\left(\mathrm{R}^{2}\right)$, RMSE, and relative error values of all response parameters are satisfactory compared to experimental uncertainty, showing great adequacy to experimental data.

Acknowledgements $\mathrm{G}$. Pintaude acknowledges $\mathrm{CNPq}$ for the grant through Project no. 308416/2017-1. Authors thank IFSC through Application no. 05/2015/PROPPI. They also thank CMCM-UTFPR for the facilities in the characterization of materials.

\section{Materials availability Not applicable}

Author contribution Conceptualization: IVT, FHGC, SS, MKG, DYP; methodology: IVT, FHGC, GP; investigations: IVT, FHGC, GP writing, original draft: IVT, FHGC, SS, MKG, DYP, GP; writing, review, and editing: all the authors; supervision: GP.

Funding Not applicable

Data availability Not applicable

\section{Declarations}

Ethics approval and consent to participate Not applicable

Consent for publication The copyright permissions have been taken and consent to submit has been received explicitly from all co-authors.

Competing interests The authors declare no competing interests.

Open Access This article is licensed under a Creative Commons Attribution 4.0 International License, which permits use, sharing, adaptation, distribution and reproduction in any medium or format, as long as you give appropriate credit to the original author(s) and the source, provide a link to the Creative Commons licence, and indicate if changes were made. The images or other third party material in this article are included in the article's Creative Commons licence, unless indicated otherwise in a credit line to the material. If material is not included in the article's Creative Commons licence and your intended use is not permitted by statutory regulation or exceeds the permitted use, you will need to obtain permission directly from the copyright holder. To view a copy of this licence, visit http://creativecommons.org/licenses/by/4.0/.

\section{References}

1. Ramesh A (2010) A review paper on hardfacing processes and materials. Int J Eng Sci Technol 2:6507-6510
2. Chaidemenopoulos NG, Psyllaki PP, Pavlidou E, Vourlias G (2019) Aspects on carbides transformations of Fe-based hardfacing deposits. Surf Coat Technol 357:651-661. https://doi.org/10.1016/ j.surfcoat.2018.10.061

3. Bahoosh M, Shahverdi HR, Farnia A (2019) Abrasive wear behavior and its relation with the macro-indentation fracture toughness of an Fe-based super-hard hardfacing deposit. Tribol Lett 67:100. https://doi.org/10.1007/s11249-019-1213-4

4. Pawar S, Jha AK, Mukhopadhyay G (2019) Effect of different carbides on the wear resistance of Fe-based hardfacing alloys. Int J Refract Met Hard Mater 78:288-295. https://doi.org/10.1016/j. ijrmhm.2018.10.014

5. Ahn D-G (2013) Hardfacing technologies for improvement of wear characteristics of hot working tools: a review. Int J Precis Eng Manuf 14:1271-1283. https://doi.org/10.1007/s12541-013-0174-Z

6. Cruz-Crespo A, Fernández-Fuentes R, Ferraressi AV, Gonçalves RA, Scotti A (2016) Microstructure and abrasion resistance of Fe$\mathrm{Cr}-\mathrm{C}$ and $\mathrm{Fe}-\mathrm{Cr}-\mathrm{C}-\mathrm{Nb}$ hardfacing alloys deposited by S-FCAW and cold solid wires. Soldag Inspeção 21:342-353. https://doi.org/10. 1590/0104-9224/SI2103.09

7. D'Oliveira ASCM, Paredes RSC, Santos RLC (2006) Pulsed current plasma transferred arc hardfacing. J Mater Process Technol 171:167-174. https://doi.org/10.1016/j.jmatprotec.2005.02.269

8. Balasubramanian V, Varahamoorthy R, Ramachandran CS, Muralidharan C (2009) Selection of welding process for hardfacing on carbon steels based on quantitative and qualitative factors. Int $\mathrm{J}$ Adv Manuf Technol 40:887-897. https://doi.org/10.1007/s00170008-1406-8

9. Zhang Y, Huang J, Ye Z, Cheng Z, Li W (2017) Process optimization for novel tungsten/metal gas suspended arc welding depositing iron base self-fluxing alloy coatings. Int J Adv Manuf Technol 89: 2481-2489. https://doi.org/10.1007/s00170-016-9258-0

10. Silwal B, Walker J, West D (2019) Hot-wire GTAW cladding: inconel 625 on 347 stainless steel. Int J Adv Manuf Technol 102: 3839-3848. https://doi.org/10.1007/s00170-019-03448-0

11. Wang H, Hu S, Wang Z, Xu Q (2016) Arc characteristics and metal transfer modes in arcing-wire gas tungsten arc welding. Int $\mathrm{J}$ Adv Manuf Technol 86:925-933. https://doi.org/10.1007/s00170-0158228-2

12. e Silva RHG, dos Santos Paes LE, Okuyama MP et al (2018) TIG welding process with dynamic feeding: a characterization approach. Int J Adv Manuf Technol 96:4467-4475. https://doi.org/10.1007/ s00170-018-1929-6

13. Lemke JN, Rovatti L, Colombo M, Vedani M (2016) Interrelation between macroscopic, microscopic and chemical dilution in hardfacing alloys. Mater Des 91:368-377. https://doi.org/10.1016/ j.matdes.2015.11.117

14. Balasubramanian V, Lakshminarayanan AK, Varahamoorthy R, Babu S (2008) Understanding the parameters controlling plasma transferred arc hardfacing using response surface methodology. Mater Manuf Process 23:674-682. https://doi.org/10.1080/ 15560350802316744

15. Jahanzaib M, Hussain S, Wasim A, Aziz H, Mirza A, Ullah S (2017) Modeling of weld bead geometry on HSLA steel using response surface methodology. Int J Adv Manuf Technol 89: 2087-2098. https://doi.org/10.1007/s00170-016-9213-0 
16. Giridharan PK, Murugan N (2009) Optimization of pulsed GTA welding process parameters for the welding of AISI 304L stainless steel sheets. Int J Adv Manuf Technol 40:478-489. https://doi.org/ 10.1007/s00170-008-1373-0

17. Pujari KS, Patil DV, Mewundi G (2018) Selection of GTAW process parameter and optimizing the weld pool geometry for AA 7075-T6 aluminium alloy. Mater Today Proc 5:25045-25055. https://doi.org/10.1016/j.matpr.2018.10.305

18. Nagesh DS, Datta GL (2010) Genetic algorithm for optimization of welding variables for height to width ratio and application of ANN for prediction of bead geometry for TIG welding process. Appl Soft Comput 10:897-907. https://doi.org/10.1016/j.asoc.2009.10.007

19. Zheng P, Wang H, Sang Z et al (2018) Smart manufacturing systems for Industry 4.0: conceptual framework, scenarios, and future perspectives. Front Mech Eng 13:137-150. https://doi.org/10.1007/ s11465-018-0499-5

20. Abubakr M, Abbas AT, Tomaz I, Soliman MS, Luqman M, Hegab $\mathrm{H}$ (2020) Sustainable and smart manufacturing: an integrated approach. Sustainability 12:2280. https://doi.org/10.3390/ su12062280

21. Fahle S, Prinz C, Kuhlenkötter B (2020) Systematic review on machine learning (ML) methods for manufacturing processes identifying artificial intelligence (AI) methods for field application. Procedia CIRP 93:413-418. https://doi.org/10.1016/j.procir.2020. 04.109

22. Muthu Krishnan M, Maniraj J, Deepak R, Anganan K (2018) Prediction of optimum welding parameters for FSW of aluminium alloys AA6063 and A319 using RSM and ANN. Mater Today Proc 5:716-723. https://doi.org/10.1016/j.matpr.2017.11.138

23. Vangalapati M, Balaji K, Gopichand A (2019) ANN modeling and analysis of friction welded AA6061 aluminum alloy. Mater Today Proc 18:3357-3364. https://doi.org/10.1016/j.matpr.2019.07.258

24. Chang Y, Yue J, Guo R, Liu W, Li L (2020) Penetration quality prediction of asymmetrical fillet root welding based on optimized BP neural network. J Manuf Process 50:247-254. https://doi.org/ 10.1016/j.jmapro.2019.12.022

25. Joseph J, Muthukumaran S (2017) Optimization of activated TIG welding parameters for improving weld joint strength of AISI 4135 PM steel by genetic algorithm and simulated annealing. Int J Adv Manuf Technol 93:23-34. https://doi.org/10.1007/s00170-0157599-8

26. Sudhakaran R, Sakthivel PSS (2013) Prediction of weld bead geometry in chromium-manganese stainless steel gas tungsten arc welded plates using artificial neural networks. Int J Manuf Mater Mech Eng 3:13-41. https://doi.org/10.4018/ijmmme.2013070102

27. Ghanty P, Paul S, Mukherjee DP, Vasudevan M, Pal NR, Bhaduri AK (2007) Modelling weld bead geometry using neural networks for GTAW of austenitic stainless steel. Sci Technol Weld Join 12: 649-658. https://doi.org/10.1179/174329307X238399

28. Lei Z, Shen J, Wang Q, Chen Y (2019) Real-time weld geometry prediction based on multi-information using neural network optimized by PCA and GA during thin-plate laser welding. J Manuf Process 43:207-217. https://doi.org/10.1016/j.jmapro.2019.05.013

29. Dey V, Pratihar DK, Datta GL, Jha MN, Saha TK, Bapat AV (2009) Optimization of bead geometry in electron beam welding using a Genetic Algorithm. J Mater Process Technol 209:11511157. https://doi.org/10.1016/j.jmatprotec.2008.03.019

30. Saha A, Mondal SC (2017) Multi-objective optimization of manual metal arc welding process parameters for nano-structured hardfacing material using hybrid approach. Measurement 102:80 89. https://doi.org/10.1016/j.measurement.2017.01.048

31. Prakash C, Singh S, Singh M, Gupta MK, Mia M, Dhanda A (2019) Multi-objective parametric appraisal of pulsed current gas tungsten arc welding process by using hybrid optimization algorithms. Int $\mathrm{J}$ Adv Manuf Technol 101:1107-1123. https://doi.org/10.1007/ s00170-018-3017-3

32. Rodriguez BR, Miranda A, Gonzalez D, Praga R, Hurtado E (2020) Maintenance of the austenite/ferrite ratio balance in GTAW DSS joints through process parameters optimization. Materials (Basel) 13:780. https://doi.org/10.3390/ma13030780

33. Correia DS, Gonçalves CV, Da Cunha SS, Ferraresi VA (2005) Comparison between genetic algorithms and response surface methodology in GMAW welding optimization. J Mater Process Technol 160:70-76. https://doi.org/10.1016/j.jmatprotec.2004.04. 243

34. Chakraborti D, Biswas P, Pal BB (2013) FGP approach for solving fractional multiobjective decision making problems using GA with tournament selection and arithmetic crossover. Procedia Technol 10:505-514. https://doi.org/10.1016/j.protcy.2013.12.389

35. Bhunia AK, Samanta SS (2014) A study of interval metric and its application in multi-objective optimization with interval objectives. Comput Ind Eng 74:169-178. https://doi.org/10.1016/j.cie.2014. 05.014

36. Kilıç H, Yüzgeç U (2019) Tournament selection based antlion optimization algorithm for solving quadratic assignment problem. Eng Sci Technol Int J 22:673-691. https://doi.org/10.1016/j.jestch. 2018.11.013

37. Shanmugam R, Murugan N (2006) Effect of gas tungsten arc welding process variables on dilution and bead geometry of Stellite 6 hardfaced valve seat rings. Surf Eng 22:375-383. https://doi.org/10.1179/174329406X126726

38. Tarng YS, Yang WH (1998) Optimisation of the weld bead geometry in gas tungsten arc welding by the Taguchi method. Int J Adv Manuf Technol 14:549-554. https://doi.org/10.1007/BF01301698

39. Günther K, Bergmann JP, Suchodoll D (2018) Hot wire-assisted gas metal arc welding of hypereutectic $\mathrm{FeCrC}$ hardfacing alloys: microstructure and wear properties. Surf Coat Technol 334:420 428. https://doi.org/10.1016/j.surfcoat.2017.11.059

40. Pei Y, De Hosson JT (2000) Functionally graded materials produced by laser cladding. Acta Mater 48:2617-2624. https://doi. org/10.1016/S1359-6454(00)00065-3

41. Han Q, Li D, Sun H, Zhang G (2019) Forming characteristics of additive manufacturing process by twin electrode gas tungsten arc. Int J Adv Manuf Technol 104:4517-4526. https://doi.org/10.1007/ s00170-019-04314-9

42. Bahoosh M, Shahverdi HR, Farnia A (2018) Macro-indentation fracture mechanisms in a super-hard hardfacing Fe-based electrode. Eng Fail Anal 92:480-494. https://doi.org/10.1016/j.engfailanal. 2018.06.021

43. Choo S-H, Kim CK, Euh K, Lee S, Jung JY, Ahn S (2000) Correlation of microstructure with the wear resistance and fracture toughness of hardfacing alloys reinforced with complex carbides. Metall Mater Trans A 31:3041-3052. https://doi.org/10.1007/ s11661-000-0083-5

Publisher's note Springer Nature remains neutral with regard to jurisdictional claims in published maps and institutional affiliations. 